\title{
$\mathrm{BMJ}$
}

\section{Continuous positive airway pressure as treatment for systemic hypertension in people with obstructive sleep apnoea: randomised controlled trial}

\begin{abstract}
Joaquín Durán-Cantolla, respiratory physician,, ${ }^{1,2}$ Felipe Aizpuru, epidemiologist, ${ }^{3,4}$ Jose María Montserrat, respiratory physician, ${ }^{5,6}$ Eugeni Ballester, respiratory physician, ${ }^{5,6}$ Joaquín Terán-Santos, respiratory physician, ${ }^{6,7}$ Jose Ignacio Aguirregomoscorta, respiratory physician, ${ }^{8}$ Mónica Gonzalez, respiratory physician, ${ }^{9}$ Patricia Lloberes, respiratory physician, ${ }^{6,10}$ Juan Fernando Masa, respiratory physician, ${ }^{6,11}$ Mónica De La Peña, respiratory physician, ${ }^{6,12}$ Santiago Carrizo, respiratory physician,, ${ }^{6,13}$ Mercedes Mayos, respiratory physician, ${ }^{14}$ Ferrán Barbé, respiratory physician, ${ }^{2,6}$ on behalf of the Spanish Sleep and Breathing Group
\end{abstract}

\section{Sleep Unit, Hospital Universitario Txagorritxu, Facultad de Medicina, Universidad del País Vasco, Vitoria 01009, Spain \\ ${ }^{2}$ Department of Respiratory Medicine, IRBlleida, Lleida 25198, Spain \\ ${ }^{3}$ Araba Research Unit, Hospital Universitario Txagorritxu \\ ${ }^{4}$ Ciber de Epidemiología y Salud Pública (CiberEsp), Instituto de la Salud Carlos III, Madrid, Spain ${ }^{5}$ Sleep Unit, Department of Respiratory Medicine, Hospital Clínic de Barcelona, Barcelona 08036, Spain \\ ${ }^{6}$ Ciber de Enfermedades Respiratorias (CibeRes), Instituto de la Salud Carlos III, Madrid \\ ${ }^{7}$ Department of Respiratory and Sleep Medicine, Hospital General Yagüe, Burgos 09005, Spain \\ SSleep Unit, Department of Respiratory Medicine, Hospital de Galdakano, Vizcaya 48960, Spain \\ ${ }^{9}$ Department of Respiratory and Sleep Medicine, Hospital Universitario Marqués de Valdecilla, Santander 39008, Spain \\ ${ }^{10}$ Sleep Unit. Department of Respiratory Medicine, Hospital Valle de Hebrón, Barcelona 08035 \\ ${ }^{11}$ Sleep Unit, Department of Respiratory Medicine, Hospital San Pedro de Alcántara, Cáceres 10003 Spain \\ ${ }^{12}$ Sleep Unit, Department of Respiratory Medicine Hospital Son Dureta, Palma de Mallorca 07014 Spain \\ ${ }^{13}$ Sleep Unit, Department of Respiratory Medicine, Hospita Universitario Miguel Server, Zaragoza 50009, Spain \\ ${ }^{14}$ Sleep Unit, Department of Respiratory Medicine, Hospital de San Pablo, Barcelona 08030 \\ Correspondence to: \\ J Duran-Cantolla \\ joaquin.durancantolla@gmail.com}

Cite this as: BMJ 2010;341:c5991 doi:10.1136/bmi.c5991

\section{ABSTRACT}

Objective To assess the effect of continuous positive airway pressure (CPAP) on 24 hour ambulatory blood pressure monitoring values in a large number of patients with untreated systemic hypertension of new onset and obstructive sleep apnoea.

Design Multicentre, double blind, randomised, placebo controlled trial.

Setting Eleven general hospitals in Spain between 2004 and 2007.

Participants 340 patients recently diagnosed as having systemic hypertension by a general practitioner (systolic blood pressure $\geq 140 \mathrm{~mm} \mathrm{Hg}$, diastolic blood pressure $\geq 90 \mathrm{~mm} \mathrm{Hg}$, or both) and an apnoea-hypopnoea index per hour of sleep of $>15$ events/hour.

Intervention Patients were assigned to CPAP $(n=169)$ or sham CPAP $(n=171)$ for three months.

Main outcome measurements Net changes in the different 24 hour ambulatory blood pressure monitoring values from baseline to three months of optimal or sham CPAP.

Results 277 ( $81 \%$ ) of the 340 patients randomised were men; the patients had a mean age of 52.4 (SD 10.5) years, a body mass index of 31.9 (5.7), an Epworth sleepiness scale score of 10.1 (4.3), an apnoea-hypopnoea index of 43.5 (24.5). No differences between groups were seen at baseline. Compared with placebo and analysed by intention to treat, the mean 24 hour ambulatory blood pressure of the CPAP group decreased by 1.5 (95\% confidence interval: 0.4 to 2.7$) \mathrm{mm} \mathrm{Hg}(P=0.01)$. The mean 24 hour ambulatory blood pressure monitoring measures decreased by $2.1 \mathrm{~mm} \mathrm{Hg}(0.4$ to 3.7$) \mathrm{mm} \mathrm{Hg}$ $(P=0.01)$ for systolic pressure and $1.3(0.2$ to 2.3$) \mathrm{mm} \mathrm{Hg}$ $(P=0.02)$ for diastolic blood pressure. Mean nocturnal blood pressure decreased by 2.1 (0.5 to 3.6) $\mathrm{mm} \mathrm{Hg}$ $(\mathrm{P}=0.01)$.

Conclusions CPAP produced a statistically significant reduction in blood pressure in patients with systemic hypertension and obstructive sleep apnoea. This reduction is small and did not achieve the $3 \mathrm{~mm} \mathrm{Hg}$ drop in mean 24 hour ambulatory blood pressure that the trial was powered to detect. Consequently, these results may have uncertain clinical relevance. However, taking into account the prevalence of hypertension and the likelihood of comorbidities, the decrease in blood pressure, although minimal, may be beneficial. Trial registration Clinical trials NCT00202527.

\section{INTRODUCTION}

Obstructive sleep apnoea is a common disorder, characterised by repetitive episodes of upper airway obstruction, which can cause poor health status with increased comorbidity and mortality, primarily due to cardiovascular causes. ${ }^{1-10}$ Systemic hypertension has been suggested as one of the major causes of cardiovascular disease in patients with obstructive sleep apnoea, and large scale epidemiological studies have shown that obstructive sleep apnoea is associated with systemic hypertension and cardiovascular complications. ${ }^{21-14}$ However, few high quality prospective observational studies have examined this question, and only two longitudinal studies have been done. One of these found a clear association between obstructive sleep apnoea and new cases of systemic hypertension, ${ }^{11}$ and the other failed to show any association. ${ }^{15}$ In this second study, systemic hypertension was seen only in overweight patients. ${ }^{15}$ The data on the incidence of the disease are therefore not clear, probably primarily owing to associated comorbidities such as obesity.

Continuous positive airway pressure (CPAP) is the best treatment for obstructive sleep apnoea ${ }^{16}$; the most accepted indication for CPAP is symptomatic obstructive sleep apnoea. Theoretically, if obstructive sleep apnoea is a cause of systemic hypertension, CPAP treatment should improve blood pressure control. Randomised clinical trials can confirm this hypothesis, and data from systematic reviews and meta-analyses 
show a small but consistent reduction in blood pressure. ${ }^{16-21}$ However, the effect of CPAP treatment on blood pressure was highly variable. This heterogeneity could have several causes: most of the studies were done in small samples; almost all the studies were done in single institutions, reflecting local characteristics; most studies have been carried out in men; the methods used for measuring blood pressure (24 hour ambulatory blood pressure monitoring or office blood pressure measurement) varied between the studies; studies included patients with and without hypertension, as well as different types of hypertension and treatments; the methods used to establish a diagnosis of obstructive sleep apnoea and the definition of hypopnoeas varied; the presence or absence of hypersomnolence and the criteria used for its evaluation or concomitant comorbidity varied; the studies had either crossover or parallel designs; studies used pills, sham CPAP, sub-therapeutic CPAP, or conservative treatment in control participants; and the duration of treatment varied between one and 52 weeks. In summary, meta-analyses of randomised trials are only as good as the trials on which they are based, and many of the trials were not done in the patients most likely to benefit, which could explain the heterogeneity of the results. The greatest benefit is likely to be seen in patients with obstructive sleep apnoea who already have untreated systemic hypertension and are thus likely to be more sensitive to treatment of systemic hypertension as a result of amelioration of obstructive sleep apnoea.

As systemic hypertension and obstructive sleep apnoea are very common diseases with high morbidity and mortality, clarifying the effect of CPAP on these patients is very important. Accordingly, our study has been designed to minimise the limitations and shortcomings seen in previous studies and to use an adequate number of patients. We did a multicentre controlled trial in patients with moderate to severe obstructive sleep apnoea and recently diagnosed but untreated systemic hypertension. We aimed to assess whether CPAP treatment produces a significant reduction in 24 hour ambulatory blood pressure and whether it could play an important role in the treatment of systemic hypertension in patients with obstructive sleep apnoea.

\section{METHODS}

\section{Patients}

We included men and women aged between 18 and 75 years who had just been diagnosed as having systemic hypertension by a general practitioner using cuff measurements, ${ }^{8}$ but had not been treated, and who were habitual snorers. We excluded patients if they had secondary systemic hypertension, had blood pressure over 180/110 mm Hg, had cognitive deterioration, were professional drivers or handled dangerous machinery, worked shifts, were pregnant, or had life threatening obstructive sleep apnoea or a severe chronic disease. We also excluded patients previously treated for obstructive sleep apnoea and patients with any contraindication for prescribing CPAP. Patients who used antihypertensive drugs, psychotropic drugs, stimulants, antidepressants, or illicit drugs or drank alcohol to excess were also excluded.

\section{Protocol design}

This was a multicentre, randomised, prospective, double blind, parallel study controlled by placebo (sham CPAP) in patients from 11 hospitals in Spain. General practitioners recruited patients with untreated, newly diagnosed systemic hypertension and snoring and sent them to the hospitals' sleep laboratories. Systemic hypertension was diagnosed according to standard criteria and was defined as systolic blood pressure of at least $140 \mathrm{~mm} \mathrm{Hg}$, diastolic blood pressure of at least $90 \mathrm{~mm} \mathrm{Hg}$, or both. ${ }^{22}$ Consecutive patients who met all the inclusion criteria were invited to undergo full polysomnography. Patients were randomised if they had an apnoea-hypopnoea index of 15 events/hour or more. We did a physical examination and recorded patients' medical history, and we recorded the Epworth sleepiness scale and EuroQol scores at baseline and at six and 12 weeks. We did 24 hour ambulatory blood pressure monitoring according to the standard recommendations. ${ }^{22}$

An external unit- the Health Research Unit of the Txagorritxu Hospital-generated the allocation sequence, using a computerised randomisation procedure. When an eligible patient was identified, the clinician sent the patient's identification information (date of birth, sex, and initials) by email, and the group assignation to either optimal therapeutic CPAP or sham CPAP was returned within 24 hours. Each patient signed a consent form before being included in the study, and all patients were informed about both arms of the trial (CPAP and sham CPAP as placeboCPAP at a very low pressure $\left(<1 \mathrm{~cm} \mathrm{H}_{2} 0\right)$ without any known therapeutic effect). We also ran teaching and training sessions (with CPAP and sham) before titration of optimal CPAP. Patients remained blinded as to whether they were receiving $\mathrm{CPAP}$ or sham, and systemic hypertension was not treated with drugs during the study. The doctors and nurses who assessed the patients in outpatient clinics did not receive any information about the treatment arm. Sham CPAP was prepared separately and distributed to CPAP machines, with no apparent differences between optimal CPAP and sham CPAP. We specifically instructed doctors and nurses not to try to obtain any information that might indicate which arm of treatment the patient was assigned to. Only sleep clinic nurses who maintained the machines and assisted patients at home had information about treatment (CPAP $v$ sham), but they were not involved in outcome assessments. After six and 12 weeks of treatment, a new 24 hour ambulatory blood pressure monitoring measurement was done, with the patients still on the allocated treatment (CPAP or sham). The main outcome variables were net changes in the different 24 hour ambulatory blood pressure monitoring values from baseline to three months of optimal or sham CPAP. 
Table 1|Characteristics of patients at baseline. Values are means (SD) unless stated otherwise

\begin{tabular}{|c|c|c|}
\hline Characteristics & CPAP $(n=169)$ & Sham $(n=171)$ \\
\hline Age (years) & $53.2(10.2)$ & $51.7(10.8)$ \\
\hline No (\%) male & $133(79)$ & $144(84)$ \\
\hline Body mass index $\left(\mathrm{kg} / \mathrm{m}^{2}\right)$ & $31.9(5.7)$ & $31.9(5.8)$ \\
\hline Epworth sleepiness scale (0-24) & $10.3(4.2)$ & $9.8(4.4)$ \\
\hline No (\%) active smokers & $49(29)$ & $39(23)$ \\
\hline Alcohol consumption (g/day of ethanol) & $22.9(26.4)$ & $19.7(22.5)$ \\
\hline Caffeine consumption (cups/day of coffee) & $1.5(1.3)$ & $1.5(1.4)$ \\
\hline \multicolumn{3}{|l|}{ Office blood pressure: } \\
\hline Systolic blood pressure (mm Hg) & $131.1(11.6)$ & $128.8(11.4)$ \\
\hline Diastolic blood pressure $(\mathrm{mm} \mathrm{Hg})$ & $82.5(8.0)$ & $81.8(8.6)$ \\
\hline \multicolumn{3}{|l|}{24 hour ambulatory blood pressure monitoring: } \\
\hline Diurnal systolic blood pressure (mm Hg) & $135.1(12.1)$ & $132.5(11.3)$ \\
\hline Nocturnal systolic blood pressure $(\mathrm{mm} \mathrm{Hg})$ & $123.3(13.3)$ & $121.4(14.1)$ \\
\hline Diurnal diastolic blood pressure $(\mathrm{mm} \mathrm{Hg})$ & $85.7(8.5)$ & $84.7(9.2)$ \\
\hline Nocturnal diastolic blood pressure (mm Hg) & $76.1(9.1)$ & $76.0(10.1)$ \\
\hline Mean 24 hour blood pressure $(\mathrm{mm} \mathrm{Hg})$ & $98.7(8.4)$ & $97.5(8.9)$ \\
\hline No (\%) hypertensive & $108(64)$ & $96(56)$ \\
\hline \multicolumn{3}{|l|}{ Polysomnographic variables: } \\
\hline Apnoea-hypopnoea index (No/hour of sleep) & $44.5(24.6)$ & $42.5(24.5)$ \\
\hline Mean $\mathrm{SaO}_{2}$ during sleep (\%) & $89.5(5.5)$ & $90.1(4.5)$ \\
\hline Lowest $\mathrm{SaO}_{2}$ during sleep (\%) & $79.9(9.3)$ & $80.1(10.6)$ \\
\hline Sleep time with $\mathrm{SaO}_{2}<90 \%$ (\%) & $13.2(20.3)$ & $10.6(16.1)$ \\
\hline Total sleep (minutes) & $448.2(42.9)$ & $447.6(45.8)$ \\
\hline Sleep N1 (minutes) & $47.1(54.0)$ & $42.2(42.1)$ \\
\hline Sleep N2 (minutes) & $207.9(67.4)$ & $206.4(70.8)$ \\
\hline Sleep N3 (minutes) & $39.7(37.9)$ & $41.9(40.8)$ \\
\hline REM sleep (minutes) & $51.0(29)$ & $52.8(30)$ \\
\hline Arousal from sleep (No/hour of sleep) & $39.8(22.7)$ & $37.2(24)$ \\
\hline
\end{tabular}

$\mathrm{CPAP}=$ continuous positive airway pressure; $\mathrm{SaO}_{2}=$ arterial oxygen saturation.

\section{Procedures}

Sleep studies

Full overnight polysomnography was done in the sleep laboratories of the participating centres according to international recommendations. ${ }^{23}$ Sleep stages, arousal, oxygen saturation, apnoeas, and hypopnoeas were scored by using conventional criteria. ${ }^{2324} \mathrm{We}$ defined an apnoea as a complete $(>90 \%)$ cessation of airflow of at least 10 seconds and a hypopnoea as any discernible reduction in airflow (around 50\%) for at least 10 seconds, along with a drop in oxygen saturation of more than $3 \%$, an electroencephalographic arousal, or both. We considered the polysomnography recording to be valid for scoring if the total sleep time was longer than 180 minutes.

\section{CPAP treatment}

We titrated optimal CPAP by using auto-CPAP (Autoset-T; ResMed, Sydney, Australia), according to a previous validation by the Spanish Sleep and Breathing Group. $^{24}$ The optimal pressure was determined visually from the raw data, and patients were sent home with this pressure for 12 weeks. Patients assigned to sham CPAP received this treatment at home for 12 weeks, using the method described by Farré et al. ${ }^{25}$ We assessed compliance with CPAP (both optimal and sham) from the device counter. We checked for side effects and any problems with the treatment at one, four, six, and 12 weeks.

\section{4 hour ambulatory blood pressure monitoring}

We recorded 24 hour ambulatory blood pressure monitoring with a Spacelabs model 90207. The cuff was programmed to inflate every 20 minutes between 6 am and $10 \mathrm{pm}$ ("daytime") and every 30 minutes between $10 \mathrm{pm}$ and 6 am ("night-time"), and the blood pressure data were processed automatically. We recorded 24 hour ambulatory blood pressure monitoring data at baseline and at six and 12 weeks. We made the diagnosis of systemic hypertension by 24 hour ambulatory blood pressure monitoring according to standard criteria $^{22}$; we defined it as systolic blood pressure $135 \mathrm{~mm} \mathrm{Hg}$ or above, diastolic blood pressure $85 \mathrm{~mm} \mathrm{Hg}$ or above, or both during waking hours and systolic blood pressure $120 \mathrm{~mm} \mathrm{Hg}$ or above, diastolic blood pressure $75 \mathrm{~mm} \mathrm{Hg}$ or above, or both during sleeping hours.

\section{Database}

We designed a database, accessible online, which was posted in the Respira network of the Spanish Respiratory Society (www.redrespira.net). Each participating centre could access only its own data. The principal researcher was responsible for sending all the data to the statistical committee and to external evaluators for analysis of the results.

\section{Statistical analysis}

We used SPSS version 15.0 to analyse data. We expressed continuous variables as means and standard deviations and qualitative variables as percentages. We compared the baseline characteristics of the two groups (CPAP and sham) by using two tailed unpaired $t$ tests for continuous variables and $\chi^{2}$ tests for categorical variables. We used paired $t$ tests to evaluate within group and between group changes in blood pressure

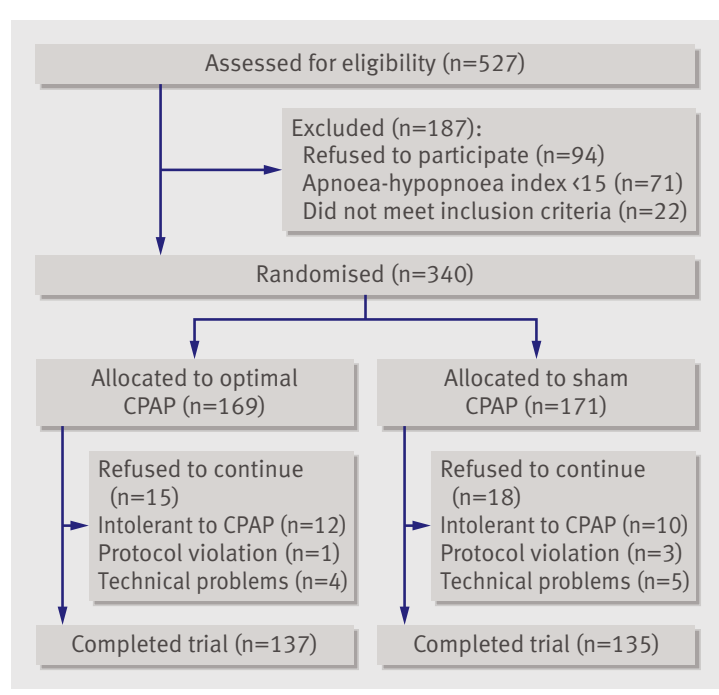

Fig 1| Flow diagram of study. $\mathrm{CPAP}=$ continuous positive airway pressure 
Table 2 |Results of 24 hour ambulatory blood pressure monitoring by changes at 6 and 12 weeks for all fully evaluable patients (CPAP, $n=169$; sham, $n=171$ )

\begin{tabular}{|c|c|c|c|c|}
\hline \multirow[b]{2}{*}{ Blood pressure measurement } & \multicolumn{2}{|c|}{ Follow-up at 6 weeks } & \multicolumn{2}{|c|}{ Follow-up at 12 weeks } \\
\hline & Difference $^{\star}(95 \% \mathrm{Cl})$ & P value $†$ & Difference $^{*}(95 \% \mathrm{Cl})$ & $P$ value $†$ \\
\hline Diurnal systolic blood pressure & $2.6(0.8$ to 4.4$)$ & 0.004 & $1.6(-0.2$ to 3.3$)$ & 0.07 \\
\hline Diurnal diastolic blood pressure & $1.8(0.7$ to 2.9$)$ & 0.001 & $1.1(-0.1$ to 2.3$)$ & 0.07 \\
\hline Diurnal mean blood pressure & 2.1 (0.8 to 3.3 ) & 0.001 & $1.3(-0.1$ to 2.5$)$ & 0.06 \\
\hline Nocturnal systolic blood pressure & $4.1(2.1$ to 6.1$)$ & $<0.001$ & 3.1 (0.9 to 5.2 ) & 0.005 \\
\hline Nocturnal diastolic blood pressure & $2.2(0.9$ to 3.5$)$ & $<0.001$ & $1.5(0.1$ to 3.0$)$ & 0.03 \\
\hline Nocturnal mean blood pressure & $2.8(1.4$ to 4.3$)$ & $<0.001$ & $2.1(0.5$ to 3.6$)$ & 0.01 \\
\hline Mean systolic blood pressure & $3.1(1.5$ to 4.7$)$ & $<0.001$ & 2.1 (0.4 to 3.7$)$ & 0.01 \\
\hline Mean diastolic blood pressure & 1.9 (1.0 to 2.9$)$ & $<0.001$ & $1.3(0.2$ to 2.3$)$ & 0.02 \\
\hline Mean blood pressure & 2.3 (1.2 to 3.4$)$ & $<0.001$ & $1.5(0.4$ to 2.7$)$ & 0.01 \\
\hline
\end{tabular}

*Differences in blood pressure $(\mathrm{mm} \mathrm{Hg}$ ) between continuous positive airway pressure (CPAP) and sham groups. †Calculated by $t$ test; compares treatment effects.

during the follow-up period. We estimated the effect size at six and 12 weeks by dividing this difference by the standard deviation of the baseline measurement. The number of patients needed for the study was set at 151 participants in each group on the basis of an assumption of an SD of 7.2 (obtained from a pilot study) for the change in mean 24 hour ambulatory blood pressure after CPAP and detection of an effect of $3 \mathrm{~mm} \mathrm{Hg}$ or greater between the CPAP and sham groups, ${ }^{26-28}$ with a power of $95 \%$ and a significance level of 5\%, using a two sided test.

The primary outcome was the net change in 24 hour ambulatory blood pressure monitoring values from baseline to three months of optimal or sham CPAP; we calculated this as the difference in the change (baseline minus follow-up) in mean values and expressed the results by intention to treat. Following widely accepted guidelines, ${ }^{29}$ we imputed missing data by using single imputation methods. In our case, we assumed that when patients withdrew from the study their blood pressure would return to baseline levels. Consequently, we used the "baseline observation carried forward" approach, which implies that the imputed changes in blood pressure for those patients with no measurements at six or 12 weeks will equal $0 \mathrm{~mm} \mathrm{Hg}$ (more unfavourable than the mean or median change observed in either the sham or CPAP arms of the study). This was, therefore, a very conservative approach in our context. We are aware that this approach underestimates the standard errors of the estimations, and we present all estimations with their confidence intervals.

An independent committee not involved in the study (Statistical Service of the Basque Health Research Institute) did two intermediate analyses, using the method proposed by O'Brien and Fleming, ${ }^{30}$ when $50 \%$ and $75 \%$ of the sample had completed the study. Stopping rules were $\mathrm{P}<0.0030$ for $50 \%$ and $\mathrm{P}<0.0163$ for $75 \%$. Therefore, to maintain the overall risk $\alpha$ of the study at the 0.05 level, we set the value of $\mathrm{P}$ for a significant result in the final analysis $<0.0307$. We sent the results of these analyses to the Health Ethics Committee of the Basque Country, which recommended continuing the study.

\section{RESULTS}

Of 527 patients who were screened between December 2004 and June 2007 (fig 1), 187 did not enter the randomisation process because they refused to participate $(\mathrm{n}=94)$, had an apnoea-hypopnoea index under 15 $(\mathrm{n}=71)$, or did not meet the inclusion criteria $(\mathrm{n}=22)$. The main cause for refusal to participate was related to work and scheduling problems for the sleep studies, 24 hour ambulatory blood pressure monitoring, and medical visits. Finally, 340 patients met the eligibility criteria, agreed to participate, and were randomised (87\% men, mean age 52.4 (SD 10.5) years, body mass index 31.9 (5.7), Epworth sleepiness scale score 10.1 (4.3), apnoea-hypopnoea index 43.5 (24.5)); 169 patients were assigned to CPAP and 171 to sham. A total of $32(19 \%)$ patients in the CPAP group and 36 $(21 \%)$ in the sham group dropped out. Intolerance of CPAP caused 12 patients in the CPAP group and 10 patients in the sham group to drop out. Table 1 shows the baseline characteristics of the two groups, which were entirely comparable.

Table 2 shows the net change in the CPAP group compared with the sham group for all the 24 hour ambulatory blood pressure monitoring variables. The reduction in mean 24 hour ambulatory blood pressure at 12 weeks was 1.5 (95\% confidence interval 0.4 to 2.7$)$ $\mathrm{mm} \mathrm{Hg}(\mathrm{P}=0.01)$ greater in the CPAP group than in the sham group. The effect was greater for systolic than for diastolic blood pressure and for nocturnal blood pressure than for diurnal blood pressure. We saw a similar reduction by the sixth week of the trial (2.3 (1.2 to 3.4) $\mathrm{mm} \mathrm{Hg} ; \mathrm{P}<0.001)$. The results improved when we restricted them to only patients who had systemic hypertension as determined by the results of the 24 hour ambulatory blood pressure monitoring, as the reduction in 24 hour ambulatory blood pressure was $1.7(0.2$ to 3.2$) \mathrm{mm} \mathrm{Hg}(\mathrm{P}=0.02)$ (see web table $\mathrm{A})$ When we considered only patients who complied with treatment (objective use of CPAP or sham CPAP for more than four hours), the 24 hour ambulatory blood pressure decreased by $2.2(0.6$ to 3.7$) \mathrm{mm}$ $\mathrm{Hg}(\mathrm{P}=0.01)$ (see web table $\mathrm{B})$. The results also improved when analysed by protocol, and the mean 24 hour ambulatory blood pressure of the CPAP group decreased by $1.9(0.5$ to 3.4$) \mathrm{mm} \mathrm{Hg}(\mathrm{P}=0.01)$ (see web table C).

Table 3 shows the main data at baseline and after six and 12 weeks of CPAP or sham treatment. The 24 hour ambulatory blood pressure monitoring showed statistically significant decreases in most blood pressure parameters for the CPAP group but not for the sham group. Figure 2 shows a simplified graphic representation of the changes in 24 hour ambulatory blood pressure monitoring from baseline to post-CPAP or post-sham treatment. We found statistically significant differences only in the CPAP group. Table 3 also shows the results of the Epworth sleepiness scale and the EuroQol scale over time. The Epworth scores improved significantly in the two groups (CPAP and sham), but the effect was greater in the CPAP group (2.2 (1.4 to 3.0); $\mathrm{P}<0.001)$. The EuroQol improved 
Table $3 \mid$ Results of 24 hour ambulatory blood pressure monitoring. Values are mean (SD) unless stated otherwise

\begin{tabular}{|c|c|c|c|c|c|c|c|c|c|c|}
\hline \multirow[b]{3}{*}{ Blood pressure measurement } & \multicolumn{5}{|c|}{ CPAP group $(n=169)$} & \multicolumn{5}{|c|}{ Sham CPAP group $(n=171)$} \\
\hline & \multicolumn{3}{|c|}{ Mean (SD) $\mathrm{mm} \mathrm{Hg}$} & \multicolumn{2}{|c|}{$\begin{array}{l}\text { Effect size } \\
\text { (SD units) }\end{array}$} & \multicolumn{3}{|c|}{ Mean (SD) $\mathrm{mm} \mathrm{Hg}$} & \multicolumn{2}{|c|}{$\begin{array}{l}\text { Effect size } \\
\text { (SD units) }\end{array}$} \\
\hline & Baseline & 6 weeks & 12 weeks & 6 weeks & 12 weeks & Baseline & 6 weeks & 12 weeks & 6 weeks & 12 weeks \\
\hline Diurnal systolic blood pressure & $135(12)$ & $132(14)^{\star \star}$ & $133(13)^{\star}$ & 0.25 & 0.19 & $132(11)$ & $132(12)$ & $132(13)$ & 0.02 & 0.06 \\
\hline Diurnal diastolic blood pressure & $86(8)$ & $84(9)^{\star \star}$ & $84(9)^{\star}$ & 0.20 & 0.15 & $85(9)$ & $85(9)$ & $85(10)$ & -0.02 & 0.01 \\
\hline Diurnal mean blood pressure & $102(9)$ & $100(10)^{\star \star *}$ & $101(10)^{\star}$ & 0.24 & 0.18 & $101(9)$ & $101(9)$ & $100(10)$ & -0.01 & 0.03 \\
\hline Nocturnal systolic blood pressure & $123(13)$ & $119(15)^{\star \star}$ & $119(14)^{\star \star}$ & 0.30 & 0.29 & $121(14)$ & $122(15)$ & $121(15)$ & -0.02 & 0.05 \\
\hline Nocturnal diastolic blood pressure & $76(9)$ & $74(10)^{\star \star}$ & $74(10)^{\star \star}$ & 0.23 & 0.25 & $76(10)$ & $76(10)$ & $75(10)$ & -0.02 & 0.07 \\
\hline Nocturnal mean blood pressure & $92(10)$ & $89(11)^{\star \star}$ & $89(10)^{\star \star}$ & 0.28 & 0.29 & $91(11)$ & $91(11)$ & $90(10)$ & -0.02 & 0.07 \\
\hline Mean 24 hour systolic blood pressure & $131(12)$ & $128(14)^{\star \star}$ & $128(13)^{\star \star}$ & 0.28 & 0.24 & $129(11)$ & $129(12)$ & $128(13)$ & 0.00 & 0.06 \\
\hline Mean 24 hour diastolic blood pressure & $83(8)$ & $81(9)^{\star \star \star}$ & $81(9)^{\star \star}$ & 0.23 & 0.20 & $82(9)$ & $82(8)$ & $82(9)$ & -0.03 & 0.03 \\
\hline Mean 24 hour blood pressure & $99(8)$ & $96(9)^{\star \star}$ & $97(9)^{\star \star}$ & 0.27 & 0.24 & $97(9)$ & $98(9)$ & $97(9)$ & -0.01 & 0.05 \\
\hline No (\%) hypertensive & $108(64)$ & $93(55)^{\star}$ & $94(56)^{\star}$ & & & $96(56)$ & $98(57)$ & $89(52)$ & & \\
\hline No (\%) non-dippers & $109(64)$ & $97(57)$ & $94(56)^{\star}$ & & & $107(63)$ & $111(65)$ & $101(59)$ & & \\
\hline Epworth sleepiness scale (1-24) & $10.4(4.2)$ & $7.6(3.8)^{\star \star}$ & $7.2(3.7)^{\star \star}$ & 0.65 & 0.74 & $9.8(4.4)$ & $8.9(4.0)^{\star \star}$ & $8.8(4.2)^{\star \star}$ & 0.21 & 0.22 \\
\hline EuroQol (visual analogue scale) & $69(15)$ & $74(14)^{\star \star}$ & $76(16)^{\star \star}$ & 0.31 & 0.38 & 72 (17) & 72 (16) & 73 (15) & 0.02 & 0.06 \\
\hline
\end{tabular}

$\mathrm{CPAP}=$ continuous positive airway pressure.

*P<0.05 compared with baseline, calculated by paired $t$ test for continuous variables or McNemar test for proportion of patients with hypertension and proportion of non-dippers

**P<0.001 compared with baseline, calculated by paired $t$ test.

significantly only in the CPAP group (4.7 (1.2 to 8.1); $\mathrm{P}=0.01)$. We did not find any associations between blood pressure changes and changes in the Epworth $(\mathrm{P}=0.11)$ or EuroQol scores $(\mathrm{P}=0.29)$. We did find a statistically significant association between compliance with CPAP and improvements in the Epworth scale $(\mathrm{P}=0.01)$ but not in quality of life as measured with EuroQol $(\mathrm{P}=0.05)$. At baseline, 109 (64\%) patients in the CPAP group and $107(63 \%)$ in the sham group showed a non-dipping pattern. After 12 weeks, 94 $(56 \%)$ patients showed this pattern in the CPAP group $(\mathrm{P}=0.02)$, but this change was not apparent in the sham group. Similarly, we found a statistically significant reduction in the percentage of patients with hypertension only in the CPAP group $(\mathrm{P}=0.04)$.

Table 4 shows compliance with CPAP and sham treatments at six and 12 weeks, expressed in hours per night, as well as compliance of more than three and four hours per night. Compliance was similar in the two groups, and we found no differences over time between the CPAP and sham groups. The level of pressure applied in the optimal CPAP group was 8.8 (SD 1.6) $\mathrm{cm} \mathrm{H}_{2}$ O. Of 340 patients, $259(76 \%)$ had some secondary effects from the treatment $(124(73 \%)$ in the CPAP group and 135 (79\%) in the sham group). Most of these effects were mild, short term, and self limiting, and we found no differences between groups. However, 12 patients in the CPAP group and 10 in the sham group discontinued the treatment because of poor tolerance.

\section{DISCUSSION}

This study shows that, in patients with a new diagnosis of systemic hypertension and obstructive sleep apnoea, 12 weeks of CPAP treatment significantly decreased 24 hour ambulatory blood pressure, with a net reduction of around $2 \mathrm{~mm} \mathrm{Hg}$, a decrease that could affect morbidity and mortality. ${ }^{3132}$ This approach might eventually modify, in certain cases, the indication for prescribing CPAP.

\section{Comparison with other studies}

Two systematic reviews, four meta-analyses including 21 randomised controlled trials, and two recent studies have evaluated the effect of CPAP treatment on blood pressure in patients with obstructive sleep apnoea. ${ }^{16-213334}$ The results showed a statistically significant net reduction in blood pressure with CPAP compared with changes in the control group, especially in patients with more severe obstructive sleep apnoea. ${ }^{18} 19$ However, some studies have shown little or no effect, $^{35-38}$ and the results are heterogeneous with large confidence intervals, from reductions as great as $36 \mathrm{~mm} \mathrm{Hg}$ to increases of $13 \mathrm{~mm} \mathrm{Hg} .{ }^{3940}$ In fact, of the 23 studies, only four included more than 100 patients. ${ }^{27343541}$ Only some of these trials had good blood pressure measurements, and few had a pre-specified primary outcome. Despite these limitations, obstructive sleep apnoea is now generally recognised to be a causal risk for systemic hypertension, ${ }^{22}$ although the association is not as strong as was once feared.

Some data suggest that people with hypersomnolence have a better response to CPAP compared with other patients, ${ }^{26-283335-394243}$ although meta-analyses and our results do not support this. ${ }^{19}$ Similarly, patients with hypersomnolence, including more hypertensive patients, showed greater reduction in blood pressure with $\mathrm{CPAP},{ }^{33}$ but this was not uniform and CamposRodriguez et al did not find that CPAP had any effect on blood pressure in hypertensive patients with somnolence. ${ }^{44}$ Moreover, in the meta-analyses, as seen in our results, no clinical variables were found to predict reductions in blood pressure with CPAP treatment. ${ }^{19}$ However, the decrease in blood pressure 
Table $4 \mid$ Compliance with treatment (intention to treat analysis)

\begin{tabular}{|c|c|c|c|c|c|c|}
\hline \multirow[b]{2}{*}{ Compliance } & \multicolumn{3}{|c|}{6 weeks } & \multicolumn{3}{|c|}{12 weeks } \\
\hline & CPAP & Sham CPAP & P value* & CPAP & Sham CPAP & P value* \\
\hline Mean (SD) compliance (hours/night) & $4.4(1.8)$ & $4.2(1.9)$ & 0.48 & $4.5(1.7)$ & $4.2(1.8)$ & 0.13 \\
\hline No (\%) complied $>3$ hours/day & $120(71)$ & $121(71)$ & 0.60 & $119(70)$ & $114(67)$ & 0.79 \\
\hline No (\%) complied >4 hours/day & $106(63)$ & $107(63)$ & 0.95 & $110(65)$ & $101(59)$ & 0.40 \\
\hline
\end{tabular}

CPAP=continuous positive airway pressure.

*Comparing CPAP with sham; intragroup comparisons of 6 weeks versus 12 weeks showed no significant differences.

was greater in patients with better compliance with CPAP. ${ }^{1534}$

Classically, people have accepted that asymptomatic patients treated with CPAP will probably have poor compliance in the absence of noticeable benefits on reduced hypersomnolence or improved quality of life. Our patients were mildly sleepy, with a slight increase in Epworth scores. They were patients with obstructive sleep apnoea and untreated hypertension recruited consecutively by general practitioners and had acceptable compliance with CPAP and dropout rates, similar to those of the sham group. However, a remaining question is the feasibility of more than 12 weeks of CPAP treatment for this symptomless hypertensive population. Barbé et al followed a large sample of hypertensive, non-sleepy patients with obstructive sleep apnoea for 12 months. ${ }^{34}$ The compliance of the group treated with CPAP was 4.7 hours/ night, which was very similar to our own results, suggesting that CPAP treatment is feasible in this population.

Data from meta-analyses suggest that the beneficial effects of CPAP on blood pressure are detectable in the first few weeks of treatment, ${ }^{18-21}$ and few studies have lasted more than 12 weeks..$^{34-36434546}$ One could argue that vascular remodelling and other structural cardiovascular changes would not be evident in short term trials of CPAP treatment and that longer treatment may be needed to obtain greater reductions in blood

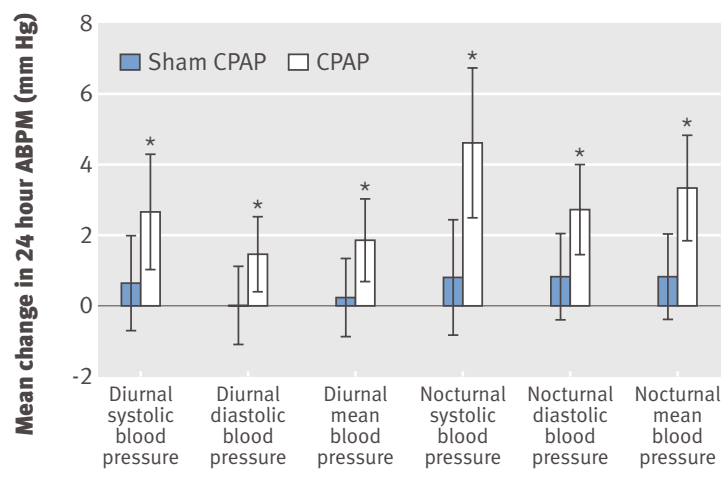

Fig 2 | Change in 24 hour ambulatory blood pressure monitoring (ABPM) values in each group after 12 weeks of treatment. Daytime blood pressure was measured from 6 am to $10 \mathrm{pm}$. Night-time blood pressure was measured from 10 $\mathrm{pm}$ to $6 \mathrm{am}$. Change was measured as mean pre-treatment minus mean post-treatment values. Positive values favour CPAP group. Bars represent mean and $95 \% \mathrm{Cl}$. Results are by intention to treat analysis. *Significant changes over time $(P<0.05)$ pressure. However, results from randomised trials have found significant reductions in blood pressure with a few weeks of CPAP treatment. ${ }^{26273342}$ We also found relevant decreases in blood pressure at six weeks in the CPAP group compared with the sham group. In spite of a non-significant decrease between weeks six and 12, the effect was still present at the end of the study. These data suggest that reductions in blood pressure are evident a few weeks after CPAP treatment.

The 24 hour ambulatory blood pressure monitoring provides a measure of the patterns of blood pressure during sleep. The prognostic value of night-time blood pressure has been found to be superior to that of daytime blood pressure. ${ }^{47} \mathrm{We}$ found a net reduction for nocturnal systolic blood pressure of $3.1 \mathrm{~mm} \mathrm{Hg}$, which could have clinical significance. In addition, 24 hour ambulatory blood pressure monitoring allowed us to identify non-dipping patients. In most people, blood pressure drops by $10-20 \%$ during the night (dippers), and people who do not show such reductions seem to be at increased risk of cardiovascular events, ${ }^{22}$ with a higher prevalence of organ damage and less favourable outcomes. ${ }^{47}$ Most patients with obstructive sleep apnoea have a non-dipping pattern, ${ }^{47}$ and we found a statistically significant reduction in the percentage of non-dipping patients only in the CPAP group. Similarly, only the group treated with CPAP showed a statistically significant percentage reduction in the number of patients with systemic hypertension. These data, despite the small effect size, could have a clinical effect.

CPAP has the well known effect of improving Epworth sleepiness scores in both sleepy and nonsleepy patients with obstructive sleep apnoea. ${ }^{162434}$ Our patients were mildly sleepy, and both treatment groups (CPAP and sham) improved significantly; this shows the importance of doing a randomised controlled trial, as any intervention can produce some improvement. The effect was significantly greater in the CPAP group, however. The EuroQol has been shown to be an effective test for measuring quality of life in patients with obstructive sleep apnoea, ${ }^{48}$ and our results show a statistically significant improvement in the EuroQol scores only in the CPAP group, although we did not find any associations between compliance with CPAP and EuroQol results. This might be caused by good baseline results on the EuroQol test. On the other hand, we found a good correlation between compliance with CPAP and improvement in Epworth scores, also suggested by other studies, ${ }^{16}$ which supports the hypothesis that symptomatic improvement 


\section{WHAT IS ALREADY KNOWN ON THIS TOPIC}

Obstructive sleep apnoea is a risk factor for systemic hypertension, which can lead to cardiovascular comorbidity and mortality

Randomised clinical trials and meta-analyses suggest that continuous positive airway pressure (CPAP) reduces blood pressure, but limitations in studies have led to heterogeneity in the data

Whether CPAP can reduce blood pressure in patients with systemic hypertension and obstructive sleep apnoea is an important question affecting a large population.

\section{WHAT THIS STUDY ADDS}

CPAP reduced blood pressure by around $2 \mathrm{~mm} \mathrm{Hg}$ in patients with untreated systemic hypertension and obstructive sleep apnoea, but an effect of this size has uncertain clinical relevance

The reduction in blood pressure was greater in patients with systemic hypertension diagnosed by 24 hour ambulatory blood pressure monitoring and in those with good compliance with CPAP

Further research is warranted to investigate whether CPAP, alone or combined with other treatments, is useful in patients with obstructive sleep apnoea and systemic hypertension

is associated with better compliance with CPAP. However, neither Epworth nor EuroQol scores were associated with changes in blood pressure, suggesting that such changes were poorly correlated with clinical symptoms or quality of life in our patients.

\section{Strengths and limitations of study}

This study had several strengths that lend confidence to our findings. Firstly, the sample was the largest multicentre trial to date, with 11 participating hospitals, and used 24 hour ambulatory blood pressure monitoring. Secondly, all patients had obstructive sleep apnoea diagnosed by polysomnography with the same method. Thirdly, patients had just been diagnosed as having systemic hypertension and had received no treatment other than conservative measures. We believe that this is a key point, as it allowed us to study the kind of patients that general practitioners usually treat, not filtered by sleep clinics or hospitals. Finally, the compliance in the sham CPAP group was the same as in the treatment group.

Some weaknesses and caveats should be mentioned. Firstly, we do not have any data on the 94 patients who refused to participate, and we cannot be sure about the magnitude of potential bias. Secondly, CPAP was titrated by using auto-CPAP and not by polysomnography. However, studies by our group have shown that these systems are comparable. ${ }^{24}$ Thirdly, the follow-up period was 12 weeks and may not be completely representative of longer periods. Fourthly, we used sham CPAP as a placebo, and we recognise that despite all the measures we took to ensure adequate blinding to allocation of patients, some patients (probably, but not certainly, in the placebo group) complained that they continued snoring. Perfect blinding of the study groups is almost impossible when using sham CPAP as a placebo; although Farré et al found that no variables change with a placebo mask, ${ }^{25}$ Rodway et al and Marshall et al found that variables may change in association with sham CPAP. ${ }^{490}$ These changes are generally small, however, with minimal clinical significance, suggesting that the use of sham CPAP as a placebo is supported in intervention studies in patients with obstructive sleep apnoea.$^{49}$ Fifthly, the magnitude of the effect was small, raising the question of how great a reduction in blood pressure is needed for it to be considered clinically relevant, ${ }^{51}$ although small decreases in blood pressure (of around $2 \mathrm{~mm} \mathrm{Hg}$, as seen in our study) might reduce cardiovascular risk. ${ }^{52}$ The effect was greater when we restricted the results to patients who had systemic hypertension according to the results of the 24 hour ambulatory blood pressure monitoring or who complied well with treatment or when we analysed the results by protocol. Finally, we did not find any clinical variables to predict the change in 24 hour ambulatory blood pressure monitoring values after CPAP. The potential mechanism by which CPAP treatment reduces blood pressure levels to a different extent in different patients with obstructive sleep apnoea is therefore unclear and is probably related to gene expression. Identifying specific markers for selecting subgroups of patients in which blood pressure levels are expected to be reduced to a greater extent with CPAP should be the next step.

\section{Conclusions}

In patients with both untreated systemic hypertension and obstructive sleep apnoea, CPAP significantly reduces blood pressure in addition to the well known beneficial effects on obstructive sleep apnoea related symptoms. This reduction was small and did not show the $3 \mathrm{~mm} \mathrm{Hg}$ drop in mean 24 hour ambulatory blood pressure that the trial was powered to detect. Consequently, these results may have uncertain clinical relevance. However, taking into account the prevalence of hypertension and the likelihood of comorbidities, the decrease in blood pressure, although minimal, may be beneficial. The reduction in blood pressure was higher in patients with systemic hypertension diagnosed by 24 hour ambulatory blood pressure monitoring (removing patients with "white coat" systemic hypertension), and also in patients who used CPAP more than three hours a night. Therefore, applying CPAP as a treatment or co-treatment in patients with both conditions, regardless of symptoms, could be useful in selected cases, although this needs to be confirmed by further studies. In addition, our results could also lead to comparative treatment trials between CPAP and antihypertensive drugs, especially in patients with different severities of systemic hypertension and obstructive sleep apnoea.

We thank Naiara Parraza and Patricia Amezua of Research Unit of Alava for advice on data analysis and preparation of the report. Spanish Sleep and Breathing Group: Amanda López-Picado, pharmacist, Araba Research Unit, Hospital Universitario Txagorritxu, Vitoria; Erika Miranda-Serrano, statistician, Araba Research Unit, Hospital Universitario Txagorritxu; Cristina Martinez-Null, biologist, Sleep Unit, Hospital Universitario, Vitoria and Ciber de Enfermedades Respiratorias (CibeRes); Ramón Rubio, neurologist, Hospital Universitario Txagorritxu, Vitoria and CibeRes; Maria Luz Alonso, respiratory physician, Hospital General Yagüe, Burgos and CibeRes; José Cordero, epidemiologist, 
Hospital General Yagüe, Burgos; Cristobal Esteban, respiratory physician, Hospital de Galdakano, Vizcaya; Antonio Jiménez, respiratory physician, Hospital Universitario Marqués de Valdecilla, Santander; Maria Rosario Carpizo, neurophysiologist, Hospital Universitario Marqués de Valdecilla, Santander; Gabriel Sanpol, respiratory physician, Hospital Valle de Hebrón, Barcelona and CibeRes; Jaime Corral, respiratory physician, Hospital San Pedro de Alcántara, Cáceres and CibeRes; Manola Rubio, respiratory physician, Hospital San Pedro de Alcántara, Cáceres; Antonia Barceló, clinical analyst, Hospital Son Dureta, Palma de Mallorca and CibeRes; Javier Piérola, biologist, Hospital Son Dureta, Palma de Mallorca and CibeRes; José María Marín, respiratory physician, Hospital Universitario Miguel Servert, Zaragoza and CibeRes. Contributors: JD-C coordinated the study and, with FA, Amanda LópezPicado, Erika Miranda-Serrano, JMM, EB, and FB, collected, processed and analysed the data. JD-C, FA, FB, and JMM designed the study and obtained funding. FA prepared the randomisation code. JD-C, FA, JMM Erika Miranda-Serrano, JT-S, JIA, MG, PL, JFM, MDLP, SC, MM, and FB supervised the study. All authors contributed to the recruitment of patients and writing of the report. All authors drafted the manuscript, revised it critically for important intellectual content, and gave final approval of the version to be published. JD-C is the guarantor. Funding: The study was sponsored by the Spanish Ministry of Health (PI041110), the Basque Government's Department of Health (20031103), and the Spanish Respiratory Society (SEPAR 2005). The sponsors had no role in the design and conduct of the study; in the collection, analysis, and interpretation of the data; or in the preparation, review, and approval of the manuscript. The opinions, results, and conclusions are those of the authors.

Competing interests: All authors have completed the Unified Competing Interest form at www.icmje.org/coi_disclosure.pdf (available on request from the corresponding author) and declare (1) No associations with any commercial entities that provided support for the work reported in the submitted manuscript; (2) No financial relationships with commercial entities that might have an interest in the submitted work; (3) No spouses, partners, or children under 18 years with relationships with commercial entities that might have an interest in the submitted work; (4) No non-financial interests that may be relevant to the submitted work. Ethical approval: The human ethics committee of each hospital approved the study protocol, and all patients gave written informed consent. Data sharing: No additional data available

1 Peppard PE, Szklo-Coxe M, Hla KM, Young T. Longitudinal association of sleep-related breathing disorder and depression. Arch Intern Med 2006;166:1709-15.

2 Marín JM, Carrizo SJ, Vicente E, Agusti AG. Long-term cardiovascular outcomes in men with obstructive sleep apnoea-hypopnoea with or without treatment with continuous positive airway pressure: an observational study. Lancet 2005;365:1046-53.

3 Ellen RL, Marshall SC, Palayew M, Molnar FJ, Wilson KG, Man-Son-Hing M. Systematic review of motor vehicle crash risk in persons with sleep apnea. J Clin Sleep Med 2006;2:193-200.

4 Tregear S, Reston J, Schoelles K, Phillips B. Obstructive sleep apnea and risk of motor vehicle crash: systematic review and metaanalysis. J Clin Sleep Med 2009;5:573-81.

5 Yaggi HK, Concato J, Kernan WN, Lichtman JH, Brass LM, Mohsenin V. Obstructive sleep apnoea as a risk factor for stroke and death. $N$ Engl J Med 2005;353:2034-41.

6 Munoz R, Duran-Cantolla J, Martinez-Vila E, Gallego J, Rubio R, Aizpuru F, et al. Severe sleep apnea and risk of ischemic stroke in the elderly. Stroke 2006;37:2317-21.

7 Johnson KG, Johnson DC. Frequency of sleep apnea in stroke and TIA patients: a meta-analysis. J Clin Sleep Med 2010;6:131-7.

8 Young T, Finn L, Peppard PE, Szklo-Coxe M, Austin D, Nieto J, et al. Sleep disordered breathing and mortality: eight-year follow-up of the Wisconsin sleep cohort. Sleep 2008;3:1071-8.

9 Marshall NS, Wong KK, Liu PY, Cullen SR, Knuiman MW, Grunstein RR. Sleep apnea as an independent risk factor for all-cause mortality: the Busselton Health Study. Sleep 2008;31:1079-85.

10 Punjabi NM, Caffo BS, Goodwin JL, Gottlieb DJ, Newman AB, O'Connor GT, et al. Sleep-disordered breathing and mortality: a prospective cohort study. PLoS Med 2009;6:e1000132.

11 Peppard PE, Young T, Palta M, Skatrud J. Prospective study of the association between sleep-disordered breathing and hypertension. N Engl J Med 2000;342:1378-84.

12 Nieto FJ, Young TB, Lind BK, Shahar E, Samet IM, Redline S, et al. Association of sleep-disordered breathing, sleep apnea, and hypertension in a large community-based study. JAMA 2000;283:1829-36.

13 Duran J, Esnaola S, Rubio R, Iztueta A. Obstructive sleep apnoeahypopnea and related clinical features in a population-based sample of subjects aged 30 to 70 yr. Am J Respir Crit Care Med 2001;163:685-9.

14 Newman AB, Nieto J, Guirdry U, Lind BK, Redline S, Pickering TG, et al. Relation of sleep-disordered breathing to cardiovascular disease risk factors: the Sleep Heart Health Study. Am J Epidemiol 2001;154:50-9.

15 O'Connor GT, Caffo B, Newman AB, Quan SF, Rapoport D, Redline S, et al. Prospective study of sleep-disordered breathing and hypertension. Am J Respir Crit Care Med 2009;179:1159-64.

16 Giles TL, Lasserson TJ, Smith B, White J, Wright JJ, Cates CJ. Continuous positive airways pressure for obstructive sleep apnoea in adults. Cochrane Database Syst Rev 2006;3:CD001106.

17 McDaid C, Durée KH, Griffin SC, Weatherly HL, Stradling JR, Davies RI, et al. A systematic review of continuous positive airway pressure for obstructive sleep apnoea-hypopnoea syndrome. Sleep Med Rev 2009;13:427-36.

18 Alajmi M, Mulgrew AT, Fox J, Davidson W, Schulzer M, Mak E, et al. Impact of continuous positive airway pressure therapy on blood pressure in patients with obstructive sleep apnoea hypopnea: a meta-analysis of randomised controlled trials. Lung 2007;185:62-72.

19 Haentjens P, Van Meerhaeghe A, Mascariello A, De Weerdt S, Poppe K, Dupont A, et al. The impact of continuous positive ainway pressure on blood pressure in patients with obstructive sleep apnoea syndrome. Arch Intern Med 2007;167:757-65.

20 Mo L, He Q. Effect of long-term continuous positive airway pressure ventilation on blood pressure in patients with obstructive sleep apnoea hypopnea syndrome: a meta-analysis of clinical trials. Zhonghua Yi Xue Za Zhi 2007;87:1177-80.

21 Bazzano LA, Khan Z, Reynolds K, He J. Effect of nocturnal nasal continuous positive airway pressure on blood pressure in obstructive sleep apnoea. Hypertension 2007;50:417-23.

22 Chobanian AV, Bakris GL, Black HR, Cushman WC, Green LA, Izzo JL, et al. Seventh report of the Joint National Committee on Prevention, Detection, Evaluation, and Treatment of High Blood Pressure. Hypertension 2003;42:1206-52.

23 Kushida CA, Litner MR, Morgenthaler T, Alessi CA, Bailey D, Coleman J, et al. Practice parameters for the indications fo polysomnography and related procedures: an update for 2005 . Sleep 2005;28:499-521.

24 Masa JF, Jimenez A, Durán J, Capote F, Monasterio C, Mayos M, et al. Alternative methods of titrating continuous positive airway pressure: large multicentre study. Am J Respir Crit Care Med 2004; 170:1218-24.

25 Farré R, Hernandez L, Montserrat JM, Rotger M, Ballester E, Navajas D. Sham continuous positive airway pressure CPAP for placebocontrolled studies in sleep apnoea. Lancet 1999;353:1154.

26 Faccenda JF, Mackay TW, Boon NA, Douglas NJ. Randomised placebo-controlled trial of continuous positive airway pressure on blood pressure in the sleep apnoea-hypopnea syndrome. Am J Respir Crit Care Med 2001;163:344-8.

27 Pepperell JC, Ramdassingh-Dow S, Crosthwaite N, Mullins R, Jenkinson C, Stradling J, et al. Ambulatory blood pressure after therapeutic and subtherapeutic nasal continuous positive airway pressure for obstructive sleep apnoea: a randomised parallel trial. Lancet 2002;359:204-10.

28 Becker HF, Jerrentrup A, Ploch T, Grote L, Penzel T, Sullivan CE, et al. Effect of nasal continuous positive airway pressure treatment on blood pressure in patients with obstructive sleep apnoea. Circulation 2003;107:68-73.

29 Committee for Medicinal Products for Human Use (CHMP). Guideline on missing data in confirmatory clinical trials. European Medicines Agency, 2009.

30 O’Brien PC, Fleming TH. A multiple testing procedure for clinical trials. Biometrics 1979;35:549-56.

31 European Trial on Reduction of Cardiac Events with Perindopril in Stable Coronary Artery Disease Investigators. Efficacy of perindopril in reduction of cardiovascular events among patients with stable coronary artery disease: randomised, double-blind, placebocontrolled, multicentre trial (the EUROPA study). Lancet 2003;362:782-8.

32 Lewington S, Clarke R, Qizilbash N, Peto R, Collins R, Prospective Studies Collaboration. Age-specific relevance of usual blood pressure to vascular mortality: a meta-analysis of individual data for one million adults in 61 prospective studies. Lancet 2002;360:1903-13.

33 Kohler M, Pepperell JC, Casadei B, Craig S, Crosthwaite N, Stradling JR, et al. CPAP and measures of cardiovascular risk in men with OSAS. Eur Respir J 2008;32:1488-96.

34 Barbé F, Durán-Cantolla J, Capote F, De La Peña M, Chiner E, Masa JF, et al. Long-term effect of continuous positive airway pressure in hypertensive patients with sleep apnea. Am J Respir Crit Care Med 2010;181:718-26.

35 Barnes M, McEvoy RD, Banks S, Tarquinio N, Murray GG, Vowles N, et al. Efficacy of positive airway pressure and oral appliance in mild 
to moderate obstructive sleep apnoea. Am J Respir Crit Care Med 2004;170:656-64.

36 Mansfield DR, Gollogly NC, Kaye DM, Richardson M, Bergin P, Naughton MT. Controlled trial of continuous positive airway pressure in obstructive sleep apnoea and heart failure. Am J Respir Crit Care Med 2004;169:361-6.

37 Barbé F, Mayoralas LR, Durán J, Masa JF, Maimó A, Montserrat JM, et al. Treatment with continuous positive airway pressure is not effective in patients with sleep apnoea but no daytime sleepiness: randomised, controlled trial. Ann Intern Med 2001;134:1015-23.

38 Robinson GV, Smith DM, Langford BA, Davies RJO, Stradling JR. Continuous positive airway pressure does not reduce blood pressure in nonsleepy hypertensive OSA patients. Eur Respir J 2006;27:1229-35.

39 Kaneko Y, Floras JS, Usui K, Plante J, Tkacova R, Kubo T, et al. Cardiovascular effects of continuous positive airway pressure in patients with heart failure and obstructive sleep apnoea. $N$ Engl J Med 2003;348:1233-41.

40 Mills PJ, Kennedy BP, Loredo JS, Dimsdale JE, Ziegler MJ. Effects of nasal continuous positive airway pressure and oxygen supplementation on norepinephrine kinetics and cardiovascular responses in obstructive sleep apnoea. J Appl Physiol 2006;100:343-8.

41 Monasterio C, Vidal S, Durán J, Ferrer M, Carmona C, Barbé F, et al. Effectiveness of continuous positive airway pressure in mild sleep apnoea-hypopnea syndrome. Am J Respir Crit Care Med 2001;164:939-43.

42 Norman D, Loredo JS, Nelesen RA, Ancoliu-Israel S, Mills PJ, Ziegler MG, et al. Effects of continuous positive airway pressure versus supplemental oxygen on 24-hour ambulatory blood pressure. Hypertension 2006;47:840-5.

43 Hui DS, To KW, Ko FW, Fok JP, Chan MC, Ngai JC, et al. Nasal CPAP reduces systemic blood pressure in patients with obstructive sleep apnoea and mild sleepiness. Thorax 2006;61:1083-90.

44 Campos-Rodríguez F, Grilo-Reina A, Perez-Ronchel J, Merino-Sánchez M, Gonzalez-Benitez MA, Beltran-Robles M, et al. Effect of continuous positive airway pressure on ambulatory BP in patients with sleep apnoea and hypertension: a placebo-controlled trial. Chest 2006;129:1459-67.

45 Arias MA, García-Río F, Alonso-Fernández A, Mediano O, Martinez I, Villamor J. Obstructive sleep apnoea syndrome affects left ventricular diastolic function: effects of nasal continuous positive airway pressure in men. Circulation 2005;112:375-83.

46 Arias MA, García-Río F, Alonso-Fernández A, Martinez I, Villamor J. Pulmonary hypertension in obstructive sleep apnoea: effects of continuous positive airway pressure: a randomised, controlled cross-over study. Eur Heart J 2006;27:1106-13.

47 Mancia G, De Backer G, Dominiczak A, Cifkova R, Fagard R, Germano G, et al. 2007 guidelines for the management of arteria hypertension: the Task Force for the Management of Arterial Hypertension of the European Society of Hypertension and the European Society of Cardiology. J Hypertens 2007;25:1105-87

48 Mar J, Rueda JR, Durán-Cantolla J, Schechter C, Chilcott J. The costeffectiveness of nasal continuous positive airways pressure treatment in patients with severe obstructive sleep apnoea. Eur Respir / 2003;21:515-22.

49 Rodway GW, Weavwe TE, Mancini C, Cater J, Maislin G, Staley B, et al. Evaluation of sham-CPAP as a placebo in CPAP intervention studies. Sleep 2010;33:260-6.

50 Marshall NS, Neil AM, Campbell AJ, Sheppard DS. Randomised controlled crossover trial of humidified continuous positive airway pressure in mild obstructive sleep apnoea. Thorax 2005;60:427-32.

51 Law MR, Morris JK, Wald NJ. Use of blood pressure lowering drugs in the prevention of cardiovascular disease: meta-analysis of 147 randomised trials in the context of expectations from prospective epidemiological studies. BMJ 2009;338:b1665.

52 Blood Pressure Lowering Treatment Trialists' Collaboration. Effects of different blood-pressure-lowering regimens on major cardiovascular events: results of prospectively designed overviews of randomised trials. Lancet 2003;362:1527-35.

Accepted: 7 September 2010 